\title{
Lack of information and access to advanced treatment for Parkinson's disease patients
}

This article was published in the following Dove Press journal:

Journal of Multidisciplinary Healthcare

9 December 2011

Number of times this article has been viewed

\section{J Lökk ${ }^{1,2}$}

'Department of Neurobiology, Caring Sciences and Society, The Karolinska Institute,

${ }^{2}$ Karolinska University Hospital Huddinge, Stockholm, Sweden
Correspondence: J Lökk

Department of Neurobiology, Caring Sciences and Society, the Karolinska Institute, Geriatric Department, Karolinska University Hospital Huddinge, SE-I4I 86, Stockholm, Sweden Tel +46858580000

Fax +46858585482

Email johan.lokk@karolinska.se
Background: Parkinson's disease (PD) patients' own knowledge and experience and access to information, in relation to advanced treatment methods, are very limited. The aim of this study was to map out PD patients' perception about various advanced treatment methods, their availability and regional differences in medical care, and to investigate patients' experience of their medication and quality of life.

Methods: A survey was sent to 4886 PD patients of the Swedish Parkinson's Disease Association covering demography, the patient's illness, current treatment, received information about advanced treatment alternatives, and health status. Advanced PD was considered as patients diagnosed $>5$ years ago, using PD medication $>5$ times/day, and experiencing motor complications $>2$ hours/day.

Results: In total, 3327/4886 persons (68\%) responded (57\% men) of which 1300 (39\%) were classified as having advanced PD. Mean age was 71 years with a median disease duration of 8 years. The treating physician was a neurologist ( $86 \%$ ) but varied between counties ( $96 \%$ to $52 \%$ ) and was most frequent in urban areas. Doctor appointments were 1.7 times/year with regional variation (2.1 to 1.1). Three out of four patients had heard of advanced treatment options and were interested, but were denied treatment. Only a small proportion of patients were informed of these by their physician. Nine percent were satisfied with their medication (including $4 \%$ of advanced patients). One third of patients experienced their general health as poor or very poor.

Conclusion: The majority of Swedish PD patients are treated by neurologists. Annual numbers of doctors' appointments were low in an international context and can partly be explained by the shortage of neurologists and other trained specialists. Doctors only provided a small proportion of patients with advanced therapy information, despite patients' interest. Hence, improvement is warranted regarding doctor appointments, information about various advanced treatment options, and their availability.

Keywords: Parkinson's disease, information, advanced disease, treatment options

\section{Background}

Parkinson's disease (PD) is the second most common neurodegenerative disease after Alzheimer's disease - both have an inevitably progressive nature. ${ }^{1}$ Age is a prominent risk factor for both diseases, as is family history of the disease. Rural living, exposure to pesticides or other toxins, and previous history of depression are other risk factors for PD whilst smoking appears to be a protective factor. ${ }^{2}$ There are as yet no treatments available which curb or cure either disease. ${ }^{3}$ Currently, all clinical treatment is for symptom relief only. The initial treatment for both diseases is medication taken orally or delivered transdermally, though in the case of PD there are 
other forms of administration, as well as brain surgery in the case of advanced disease. ${ }^{4,5}$ As the disease progresses, most PD patients eventually end up having difficulty controlling symptoms such as fluctuations, dyskinesia, and unpredictable so-called on-off episodes. ${ }^{3,6}$ These phenomena are often accompanied by non-motor symptoms from different organ systems such as the gastrointestinal and urogenital tract as well as neuropsychiatric and autonomic symptoms. ${ }^{7}$ Advanced treatment can be considered when adequate symptom relief is not provided by oral or transdermal medication. This is determined on an individual basis depending on the nature and severity of the symptoms, current and previous treatment, mental status, age, capability, and personal preference. Treatment alternatives for patients in an advanced disease state include deep brain stimulation (DBS), ${ }^{8}$ and two types of medication which are administered by continuous pump infusion. These are apomorphine, ${ }^{9}$ which is administered subcutaneously, and levodopa/carbidopa which is administered directly to the small intestine (Duodopa ${ }^{\circledR}$ [levodopa + carbidopamonohydrate for intestinal use]; Abbott Laboratories, Abbott Park, IL). ${ }^{10}$

The patients' own knowledge and experience, especially in the later stages of the disease, how they perceive their situation, and access to information in relation to advanced treatment methods have until now been very limited. ${ }^{11,12}$ For this reason, a survey was carried out among members of the Parkinson's Association to find out what information they had received about the various advanced treatment methods and their availability. The author also wanted to map out any regional differences in medical care and investigate how the patients experienced their medication and quality of life.

\section{Materials and methods}

A survey was sent to 4886 Parkinson's patients who were members of the Swedish Parkinson's Disease Association. The survey included questions about demography, the patient's illness, current treatment, what information the patient had received about advanced treatment alternatives, and who gave that information, as well as an evaluation of their own health status. All questions were answered by multiple choice, however for some questions it was also possible to write extra comments.

The survey questions focused particularly on patients with advanced PD as it is for these patients that advanced treatment may be appropriate. For inclusion in this group the following three criteria were to be met:

- PD diagnosis $>5$ years ago

- uses PD medication at least 5 times per day
- experiences wearing-off of medication effect, "on-off" problems, dyskinesia or dystonia for at least two hours per day.

The survey was anonymous, however respondents were requested to include their postal code to enable regional comparisons to be made.

This study was approved by the Regional Ethical Committee of Stockholm.

\section{Results}

The survey was completed by 3327 out of 4886 persons (68\%) without any reminders.

The respondents consisted of $57 \%$ men and $43 \%$ women, which is the approximate gender distribution among PD patients in Sweden. ${ }^{13}$ The mean age was 71 years (35-100) with median illness duration of 8 years (35-100) (Table 1). Of all respondents, 1300 (39\%) were classified as having an advanced disease state.

One factor which is crucial for the quality of care for PD patients is that the patient is seen by a specialist in the field, ie, a neurologist or geriatrician who is knowledgeable in the treatment of PD. The majority of survey respondents stated that their treating physician was a neurologist (86\%) or geriatrician (9\%). A total of $7 \%$ of respondents reported that their treating physician was a general practitioner. Patients with advanced disease were mostly treated by neurologists $(86 \%)$ and geriatricians (11\%); only $5 \%$ of patients in this group were treated by a general practitioner.

There was great regional variation regarding which type of PD specialist patients were treated by. The percentage of patients who were seen by a neurologist varied from $96 \%$ to $52 \%$ between different counties and was most frequent in the urban areas (Figure 2).

PD patients in the study saw a doctor on average 1.7 times per year. Patients in the later stages of the disease were seen a little more often, on average 1.8 times per year. A considerable regional variation was seen here, with the appointment frequency being almost twice as high in some

Table I Demographic variables of responding Parkinson's disease patients

\begin{tabular}{lll}
\hline & $\begin{array}{l}\text { PD pts, total } \\
(\mathbf{n}=\mathbf{3 3 2 6})\end{array}$ & $\begin{array}{l}\text { PD pts, advanced } \\
(\mathbf{n}=1 \mathbf{3 0 0})\end{array}$ \\
\hline Mean age & $7 \mathrm{I}(35-100)$ years & $7 \mathrm{7I}(39-100)$ years \\
Females/Males & $43 \% / 57 \%$ & $43 \% / 57 \%$ \\
Median PD duration & $8(1-46)$ years & II $(5-46)$ years \\
\hline
\end{tabular}

Abbreviations: PD, Parkinson's disease; pts, patients. 
county council regions as others (with a range of 2.1 to 1.1 appointments per year).

A little more than half of the respondents $(56 \%)$ indicated that they took some kind of anti-PD mediation more than 5 times per day. All patients in the advanced stages of the disease took medication more often than 5 times per day this was also one of the criteria for inclusion in that group. Among the other patients, 70\% took anti-PD medication 1-4 times per day (Table 2).

\section{Strong interest in advanced treatment options}

Only $9 \%$ of respondents reported that they were satisfied with their medication - among patients with advanced disease this figure was only 4\% (Figure 1). A significant number of patients also experienced their general health as poor or very poor: in the whole group $27 \%$, and among patients with advanced disease, $38 \%$.

In total around three quarters of the patients had heard of the three advanced treatment options, and in the group of patients in the later stages of the disease even more had done so (Table 3). More than half of the respondents had received information from Parkinsonjournalen, the members' magazine published by the Swedish Parkinson's Association. Other important information channels were: patient gatherings ( $25 \%$ in both the whole group and the late stages group); via television or the daily press (21\% in the whole group and $18 \%$ in the advanced disease group); and the Internet ( $8 \%$ in the whole group $6 \%$ in the advanced disease group).

Only a small proportion of patients had been informed of the three treatment options by their treating physician (Table 4) and only a little more than one in four patients in the advanced disease group had received this information from their doctor.

Among the respondents there were also some patients with experience of one of the three advanced treatment options.

Table 2 Total number of administration times per day of antiPD medication, for patients with advanced disease and for the remainder

\begin{tabular}{lllll}
\hline & $\mathbf{0}$ times & $\mathbf{I - 4}$ times & $\mathbf{5 - 9}$ times & $>$ I0 times \\
\hline Total & 32 & 1376 & 1696 & 172 \\
& $(1.0 \%)$ & $(41 \%)$ & $(51 \%)$ & $(5 \%)$ \\
Patients with & 0 & 0 & 1161 & 139 \\
advanced disease & $(0 \%)$ & $(0 \%)$ & $(89 \%)$ & $(11 \%)$ \\
Other patients & 32 & 1376 & 535 & 33 \\
& $(2 \%)$ & $(70 \%)$ & $(27 \%)$ & $(2 \%)$ \\
\hline
\end{tabular}

Abbreviation: PD, Parkinson's disease.

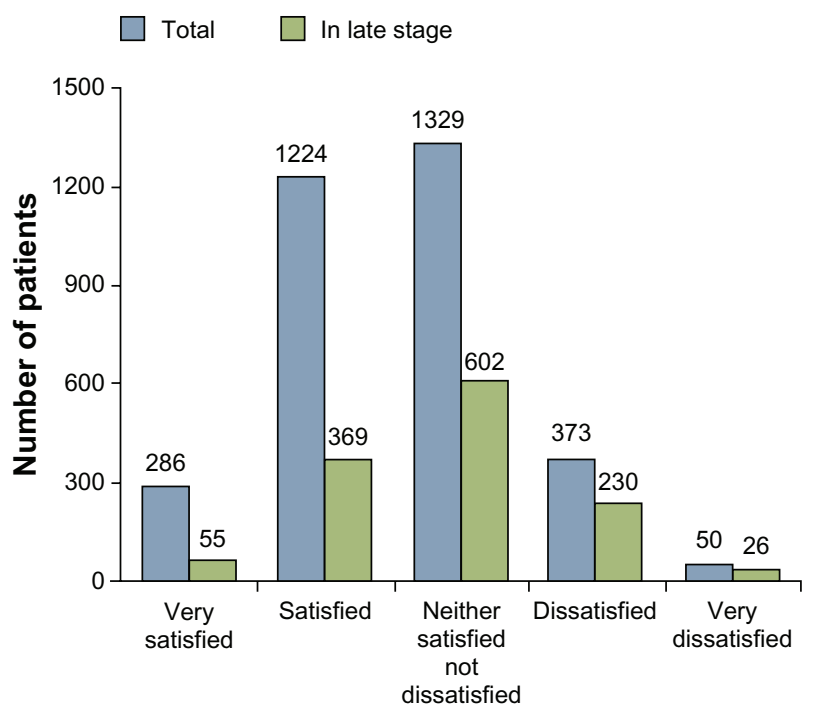

Figure I Only a small number of patients with Parkinson's disease report that they are very satisfied with their treatment.

A total of 338 patients $(10 \%)$ had received advanced treatment: DBS $(n=178 ; 5.3 \%)$, apomorphine pump $(n=83$; $2.5 \%)$ or Duodopa $(\mathrm{n}=77 ; 2.3 \%)$.

Around half of respondents (47\%) indicated that they were interested in being evaluated as to suitability for treatment with one of the treatment options mentioned above for the group of patients with advanced disease the figure was even higher (61\%).

Many patients had however already been denied this treatment for varying reasons (Table 5). The most common reason was that the treating physician was of the opinion that the patient was not sufficiently unwell. However, 46 respondents had been denied treatment for financial reasons.

\section{Discussion}

In this population of PD patients, it was found that the majority of patients were treated by physicians with specialist knowledge of the disease but that the number of doctor's visits per year was quite low and that this amount varied between different regions. The level of knowledge about advanced treatment was rather good among patients, but only one in four patients in the advanced disease group had been informed by their doctor. This may be a problem since optimal patient care with patient participation requires that patients and their families are well informed. ${ }^{14-16}$ This lack of information may also contribute to the fact that only one in ten patients were very satisfied with their current medication and that three in ten rated their health as poor. The large variation in how often patients see their doctor, 


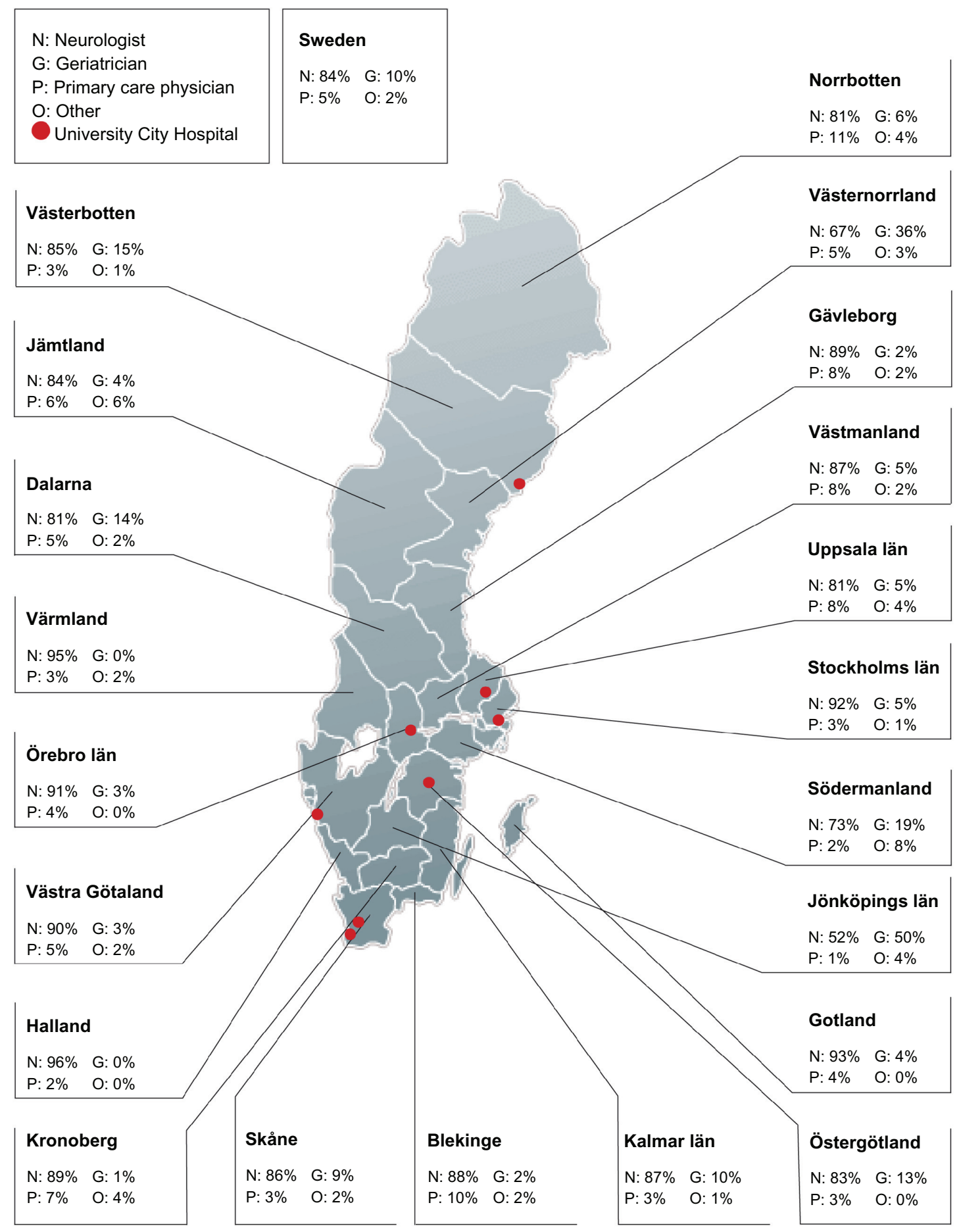

Figure 2 Percentage of patients treated by medical specialists of Parkinson's disease care in different counties of Sweden.

according to the survey results, indicates that health care is unequally distributed between different groups and different county councils. A higher frequency of doctor's visits was mostly seen in metropolitan areas where access to neurologists and geriatricians is usually greatest.

Since PD is a progressive degenerative process for which there is currently no cure, it is hardly surprising that there is such a strong interest in the advanced, symptomalleviating treatment methods available for use in advanced disease. The potential for improvement is thus great. Considering the critical importance of correct treatment for quality of life, it is surprising that only one in four patients with advanced disease had received such information from their doctor. 
Table 3 Percentage of all patients/advanced patients aware of the different treatment options for advanced Parkinson's disease

\begin{tabular}{lll}
\hline DBS/brain surgery & Yes & No \\
Total & $76 \%$ & $17 \%$ \\
Advanced disease & $81 \%$ & $13 \%$ \\
Infusion with apomorphine pump & Yes & No \\
Total & $64 \%$ & $24 \%$ \\
Advanced disease & $74 \%$ & $17 \%$ \\
Infusion with Duodopa ${ }^{\circledR}$ pump & Yes & No \\
Total & $69 \%$ & $21 \%$ \\
Advanced disease & $76 \%$ & $15 \%$ \\
\hline
\end{tabular}

Abbreviation: DBS, deep brain stimulation.

That patients are denied treatment is sometimes appropriate and this can often be motivated by the requirements and conditions which must be fulfilled for the various treatment options. For example, prior to initiation of treatment with medication delivered by pump (apomorphine and Duodopa) it must be established that the patient can manage the equipment, either by themselves or with the help of a family member. ${ }^{17,18}$ Apomorphine is furthermore considered less suitable for patients with neuropsychiatric symptoms. ${ }^{19}$ Brain surgery has an inferior effect and more side effects in older patients and is only in exceptional circumstances used in patients over the age of 70-75 years. One must also consider the high risk of adverse events with DBS including surgical site infections, and confused state of speech or impairment. ${ }^{20}$ Cognitive impairment is common in patients in the later stages of the disease and can also render DBS and Duodopa inappropriate, ${ }^{21,22}$ whereas treatment with apomorphine in this regard could be more suitable. In summary, the different treatment options can be more or less suitable for individual patients.

Given the current scientific evidence and the cost of such treatment it is hardly appropriate to initiate treatment with DBS, apomorphine pump or Duodopa at an early stage when the regular medication is working well. Moreover, physicians should also emphasize the importance of, and encourage, exercise and training as complementary treatments for PD patients as well as awareness, diagnosis, and treatment of
Table 4 Percentage of all patients/advanced patients who have received information from their treating doctor about the different treatment options for advanced Parkinson's disease

\begin{tabular}{lll}
\hline DBS/brain surgery & Yes & No \\
Total & $20 \%$ & $77 \%$ \\
Advanced disease & $27 \%$ & $73 \%$ \\
Infusion with apomorphine pump & Yes & No \\
Total & $16 \%$ & $84 \%$ \\
Advanced disease & $26 \%$ & $74 \%$ \\
Infusion with Duodopa pump & Yes & No \\
Total & $17 \%$ & $83 \%$ \\
Advanced disease & $26 \%$ & $74 \%$ \\
\hline
\end{tabular}

Abbreviation: DBS, deep brain stimulation.

non-motor symptoms, which most often do not respond to dopaminergic therapy. It can however hardly be seen as reasonable that 46 of the patients surveyed were denied treatment for financial reasons. ${ }^{23}$ It could be argued that the survey shows the patients' subjective perception of the reasons for denial of treatment, which does not necessarily correspond to the reasons which the health care provider believes they have communicated to the patient. However, these patients feel that they are not a worthwhile investment of resources.

Although an overwhelming majority of respondents indicated that they are treated by a physician with special competence in the treatment of PD, the survey also revealed that $7 \%$ of the PD patients are treated by a general practitioner. Such physicians have usually only a few PD patients in their catchment area and therefore a limited experience of the disease and its treatment. Since respondents were able to choose more than one answer it is unclear whether the neurologist or geriatrician had continuing responsibility for their treatment or whether the patient was only occasionally seen by a specialist, or alternated between two doctors. One possible explanation for the fact that not all patients in the survey had been seen by a neurologist is the great shortage of neurologists in Sweden. ${ }^{24}$ Compared to other European countries, Sweden has less neurologists per million inhabitants, with 33 versus 66 in Europe, 58 in Finland, and 49 in Norway.

Table 5 Number of PD patients being interested in advanced therapy but being denied due to noted reasons below

\begin{tabular}{lllllllllll}
\hline & $\begin{array}{l}\text { Not ill } \\
\text { enough }\end{array}$ & $\begin{array}{l}\text { Too } \\
\text { severe } \\
\text { disease }\end{array}$ & $\begin{array}{l}\text { Old } \\
\text { age }\end{array}$ & $\begin{array}{l}\text { Impaired } \\
\text { memory }\end{array}$ & $\begin{array}{l}\text { Mental } \\
\text { symptoms } \\
\text { (hallucinations, } \\
\text { depression) }\end{array}$ & $\begin{array}{l}\text { Speech } \\
\text { difficulties }\end{array}$ & $\begin{array}{l}\text { Difficulties } \\
\text { handling the } \\
\text { equipment }\end{array}$ & $\begin{array}{l}\text { Social } \\
\text { reasons }\end{array}$ & $\begin{array}{l}\text { Geographic } \\
\text { reasons }\end{array}$ & $\begin{array}{l}\text { Economic } \\
\text { reasons } \\
\text { (expensive } \\
\text { treatment) }\end{array}$ \\
\hline $\begin{array}{llllllllll}\text { Other } \\
\text { Tdvanced }\end{array}$ & 200 & 29 & 102 & 58 & 64 & 57 & 55 & 7 & 3 & 46 \\
disease & 19 & 59 & 36 & 35 & 30 & 37 & 2 & 2 & 33 & 176 \\
\hline
\end{tabular}

Abbreviation: PD, Parkinson's disease. 


\section{Limitations}

The survey provides a unique insight into patients' own experiences of their illness, the information they receive about the various treatment options, and what treatment options they are offered. In only addressing the survey to members of the Parkinson's Association a selection has of course been made. This selection can however result in only the most active patients, who have of course already shown themselves to be active enough to join the Swedish PD Association, responding to the survey. Then the results must be considered as even more discouraging since the less active non-members of the association maybe would have scored less favorably on the survey. However, the respondents constitute one sixth of the Swedish population of patients diagnosed with PD. ${ }^{13}$ The chosen method had a high response frequency without the use of reminders and respected the patients' integrity. This would not have been the case if the patients had been tracked and recruited via Swedish Pharmaceutical dispensing data regarding anti-PD medication, which could have been an alternative method.

Pharmaceutical information was not obtained from the patients, nor were any assessments of disease severity undertaken, the latter for methodological reasons. However, despite this lack of information, the patients' own experiences stated that only a minority of them were satisfied with their current medication. The same research design as that discussed here has also recently been used by German PD researchers. ${ }^{25}$

\section{Future research}

Future research should aim at mapping early diagnostic signs of PD such as smell dysfunction, REM sleep behavior disorder, and obstipation, as well as finding neuroprotective drugs. However, a current problem with early detection and diagnosis of $\mathrm{PD}$ is that there are no commercially available neuroprotective drugs, although there are some indications that MAO-B inhibitors may have such properties. ${ }^{26}$ It is likely that there is no one drug or one solution, rather, that an approach using a combination of drugs with different targets, possibly with synergistic effects, will prove effective. Also, more research should be performed on the common use and possible effects of complementary and alternative medicines, which could contribute to the armamentarium of anti-PD treatment. ${ }^{27}$

\section{Conclusion}

The majority of Swedish PD patients are treated by physicians with specialist knowledge of the disease. The number of times per year that patients are seen by a doctor is low in an international context and can most likely be explained by the shortage of neurologists and other trained specialists. This may also contribute to the regional differences shown. Doctors only provided a small proportion of patients with advanced therapy information, despite patients' interest.

This study has shown deficiencies and areas which can be improved within the area of PD management in Sweden. Knowledge of different aspects of PD will hopefully be greatly improved as a result of the Swedish National Neurology Registry which was initiated during 2011 and which will include PD. Data from the registry will be available for use by patient organizations, health care providers and decision makers, with the overall aim being the improvement of patient care.

\section{Acknowledgments}

The survey was a part of the European Parkinson's Disease Association's Parkinson's disease awareness campaign (http://www.parkinsonsawareness.eu.com) which is supported by many organizations as well as receiving financial support from several companies.

\section{Disclosure}

The author has received honoraria from Pfizer, Orion-Pharma, GlaxoSmithKline, MEDA, Boehringer-Ingelheim, and Lundbeck.

\section{References}

1. Maetzler W, Liepelt I, Berg D. Progression of Parkinson's disease in the clinical phase: potential markers. Lancet Neurol. 2009;8(12): 1158-1171.

2. Sanyal J, Chakraborty DP, Sarkar B, et al. Environmental and familial risk factors of Parkinsons disease: case-control study. Can J Neurol Sci. 2010;37(5):637-642.

3. Jancovic J, Kapadia AS. Functional decline in Parkinson's disease. Arch Neurol. 2001;58(10):1611-1615.

4. Rosa MM, Ferreira JJ, Coelho M, Freire R, Sampaio C. Prescribing pattern of antiparkinsonian agents in Europe. Mov Disord. 2010;25(8): 1053-1060.

5. Ryton BA, Liddle BJ. Implementing NICE clinical guidelines on Parkinson's disease. Clin Med. 2009;9(5):436-440.

6. Alves G, Wentzel-Larsen T, Aarsland D, Larsen JP. Progression of motor impairment and disability in Parkinson's disease: a population-based study. Neurology. 2005;65(9):1436-1441.

7. Chaudhuri KR, Shapira AH. Non-motor symptoms of Parkinson's disease: dopaminergic pathophysiology and treatment. Lancet Neurol. 2009;8(5):464-474.

8. Okun MS, Foote KD. Parkinson's disease DBS: what, when, who and why? The time has come to tailor DBS targets. Expert Rev Neurother. 2010;10(12):1847-1857.

9. Stocchi F. Use of apomorphine in Parkinson's disease. Neurol Sci. 2008;29 Suppl 5:S383-S386.

10. Fernandez HH, Odin P. Levodopa-carbidopa intestinal gel for treatment of advanced Parkinson's disease. Curr Med Res Opin. 2011;27(5): 907-919.

11. Scott B, Nyholm D. Patient-perceived retrospective outcome of duodenal levodopa infusion in advanced Parkinson's Disease. Eur Neurol J. 2010;2:3-10. 
12. Dowding CH, Shenton CL, Salek SS. A review of the health-related quality of life and economic impact of Parkinson's disease. Drugs Aging 2006;23(9):693-721.

13. Lökk J, Borg S, Svensson J, Persson U, Ljunggren G. Drug and treatment costs in Parkinson's disease patients in Sweden. Acta Neurol Scand. April 6, 2011. [Epub ahead of print.]

14. Lökk J. Caregiver strain in Parkinson's disease and the impact of disease duration. Eur J Phys Rehabil Med. 2008;44(1):39-45.

15. Pandya M, Kubu CS, Giroux ML. Parkinson's disease: not just a movement disorder. Cleve Clin J Med. 2008;75(12):856-864.

16. Peters M, Fitzpatrick R, Doll H, Playford D, Jenkinson C. Does selfreported well-being of patients with Parkinson's disease influence caregiver strain and quality of life? Parkinsonism Relat Disord. 2011; 17(5):348-352.

17. Nyholm D, Lewander T, Johansson A, Lewitt PA, Lundqvist C, Aquilonius SM. Enteral levodopa/carbidopa infusion in advanced Parkinson's disease: long-term exposure. Clin Neuropharmacol. 2008; 31(2):63-73.

18. Antonini A, Odin P. Pros and cons of apomorphine and L-dopa continuous infusion in advanced Parkinson's disease. Parkinsonism Relat Disord. 2009;15 Suppl 4:S97-S100.

19. Clarke CE, Worth P, Grosset D, Stewart D. Systematic review of apomorpine infusion, levodopa infusion and deep brain stimulation in advanced Parkinson's disease. Parkinsonism Relat Disord. 2009; 15(10):728-741.

20. Weaver FM, Follett K, Stern M, et al. CSP 468 Study Group. Bilateral deep brain stimulation vs best medical therapy for patients with advanced Parkinson disease: a randomized controlled trial. JAMA 2009;301(1):63-73.
21. Poletti M, Emre M, Bonuccelli U. Mild cognitive impairment and cognitive reserve in Parkinson's disease. Parkinsonism Relat Disord. 2011;17(8):579-586.

22. Hilker R, Antonini A, Odin P. What is the best treatment for fluctuating Parkinson's disease: continuous drug delivery or deep brain stimulation of the subthalamic nucleus? J Neural Transm. 2011;118(6): 907-914.

23. Gallagheer DA, Schrag A. Impact of newer pharmacological treatments on quality of life in patients with Parkinson's disease. CNS Drugs. 2008; 22(7):563-586.

24. Smits QA, Andsberg G, Andersen PM, Andresson M, Fredriksson S, Gunnarsson M, et al. Neurology in transition from diagnostic to therapeutic discipline. (Swedish: Neurologi i förvandling - från diagnostisk till terapeutisk disciplin). Läkartidningen. 2010;105(36): 2413-2416.

25. Müller T, Woitalla D. Quality of life, caregiver burden and insurance in patients with Parkinson's disease in Germany. Eur J Neurol. 2010; 17(11):1365-1369.

26. Olanow CW, Hauser RA, Jankovic J, et al. A randomized, doubleblind, placebo-controlled, delayed start study to assess rasagiline as a disease modifying therapy in Parkinson's disease (the ADAGIO study): rationale, design, and baseline characteristics. Mov Disord. 2008;23(15):2194-2201.

27. Lökk J, Nilsson M. Frequency, type and factors associated with the use of complementary and alternative medicine in patients with Parkinson's disease at a neurological outpatient clinic. Parkinsonism Relat Disord. 2010;16(8):540-544.
Journal of Multidisciplinary Healthcare

\section{Publish your work in this journal}

The Journal of Multidisciplinary Healthcare is an international, peerreviewed open-access journal that aims to represent and publish research in healthcare areas delivered by practitioners of different disciplines. This includes studies and reviews conducted by multidisciplinary teams as well as research which evaluates the results or conduct of such teams or

\section{Dovepress}

healthcare processes in general. The journal covers a wide range of areas and welcomes submission from practitioners at all levels, from all over the world. The manuscript management system is completely online and includes a very quick and fair peer-review system. Visit http://www.dovepress.com/testimonials.php to read real quotes from published authors. 